University of Nebraska - Lincoln

DigitalCommons@University of Nebraska - Lincoln

Architectural Engineering -- Faculty Publications

Architectural Engineering and Construction,

Durham School of

2011

\title{
A Novel Photovoltaic/Battery Structure for Solar Electrical Vehicles [PVBS for SEV]
}

\author{
Mahmoud Alahmad \\ University of Nebraska - Lincoln, malahmad2@unl.edu \\ Mohamed Amer Chaaban \\ University of Nebraska-Lincoln, mchaaban@unomaha.edu \\ Lana Chaar \\ The Petroleum Institute, lelchaar@pi.ac.ae
}

Follow this and additional works at: https://digitalcommons.unl.edu/archengfacpub

Part of the Architectural Engineering Commons

Alahmad, Mahmoud; Chaaban, Mohamed Amer; and Chaar, Lana, "A Novel Photovoltaic/Battery Structure for Solar Electrical Vehicles [PVBS for SEV]" (2011). Architectural Engineering -- Faculty Publications. 50. https://digitalcommons.unl.edu/archengfacpub/50

This Article is brought to you for free and open access by the Architectural Engineering and Construction, Durham School of at DigitalCommons@University of Nebraska - Lincoln. It has been accepted for inclusion in Architectural Engineering -- Faculty Publications by an authorized administrator of DigitalCommons@University of Nebraska Lincoln. 


\section{A Novel Photovoltaic/Battery Structure for Solar Electrical Vehicles [PVBS for SEV]}

\author{
Mahmoud Alahmad, PhD, P.E \\ Durham School of Architectural \\ Engineering and Construction \\ University of Nebraska-Lincoln \\ Omaha, Nebraska, U.S.A. \\ malahmad2@unl.edu
}

\author{
Mohamed A.Chaaban, MS \\ Student \\ Durham School of Architectural \\ Engineering and Construction \\ University of Nebraska-Lincoln \\ Omaha, Nebraska, U.S.A \\ mchaaban@unomaha.edu
}

\author{
Lana Chaar, $\mathrm{PhD}$ \\ The Petroleum Institute, \\ Department of Electrical Engineering \\ Abu Dhabi, UAE \\ lelchaar@pi.ac.ae
}

\begin{abstract}
In this paper, we propose a new flexible Photovoltaic/Battery charging Structure for Solar Electrical Vehicles (PVBS), where the interconnection of the system is dynamically changing based on current shading conditions across PV modules to provide intelligent system, as well as to provide flexibility, performance, and efficiency enhancement for the SEV. PVBS is expected to 1) provide a battery charging efficiency improvement over existing employed topologies; 2) provide new means to match the computing load with the PV system performance metrics shading and mismatches; 3 ) and provide elastic reconfigurable system expected to spur research advancements and innovations to make future SEV design smarter. A MATLAB simulation model and an actual test were conducted to verify the proposed configuration. These results show that the proposed system increases the efficiency of the traditional PV/Battery charging strategies and smoothes the shape of $P-V$ curve to a single peak in the curve.
\end{abstract}

Keywords-photovoltaic; electric vehicle; hybrid; adaptive; topology.

\section{INTRODUCTION}

Current transportation systems are heavily based on the century-old technology of internal combustion engines (ICE). Electrification is a clear trend to improve efficiency, performance, and sustainability of transportation systems. A long-term transportation electrification goal is to integrate the transportation industry with the electric power industry, generate more and more electricity from Carbon-free and renewable energy sources, and use the electricity in transportation. Electricity is cleaner, greener, more affordable, and domestically produced in many parts of the world. As the electrification level is increased in transportation, the electric power grid is getting cleaner and greener as well since more renewable energy sources provide power to the grid. This special issue is focused on transportation electrification and its smart grid and vehicle-to-grid applications.

Due to the environmental issues caused by over-reliance on fossil fuels as prime energy source of transportation and while the world population and energy consumption increase, Vehicle's Emissions are a leading cause of air, land, and water pollution. The interest in Hybrid vehicles and Solar Electrical Vehicles stems from the desire to play a part in helping build a "greener" and more energy sustainable future for our planet. Renewable energy resources are abundant, clean, cost efficient, and do not emit harmful $\mathrm{CO} 2$ gases. An alternative is to use locally available renewable energy resources (e.g. PV, fuel cell etc) and implement modular, expandable and task-oriented system concepts that guarantee cost-effective and sustainable resources of energy; there is currently a growing trend towards the more widespread use of solar energy. As of yet, few Solar Electrical Vehicles have been implemented due to their relatively high cost and modest efficiency. Although the efficiency of PV panels is currently still poor, PV energy has great potential for use in several applications including electrical vehicles.

Solar Electrical Vehicles (SEV) require various components to conduct, control, convert, store, and utilize the energy generated from the PV by combining different technologies. The design of a solar vehicle is severely limited by the amount of energy input into the car.

The SEV system generates energy from sunlight and converts this energy to high voltage which is utilized to charge the supplemental battery and the Hybrid Vehicle (HV) battery pack. This allows the Hybrid Vehicle to operate for extended driving range in the electric mode.

Although current research in the Electrical Vehicles field is focusing on improving the efficiency of the Vehicles through the development of electrical machines and alternative resources that give better performance, some researchers are looking to improve the performance of the energy storage techniques by tracking the optimal operational configuration of components In [1], reconfiguration is proposed for an electric vehicle to increase the power output and operate the load at desired conditions to improve the load efficiency. For example, during acceleration, the engine requiring additional torque is 
supplied by reconfiguring the PV in parallel to increase the current output. In [2] the author discussed the optimum switching points for array reconfiguration controller according to the irradiation conditions.

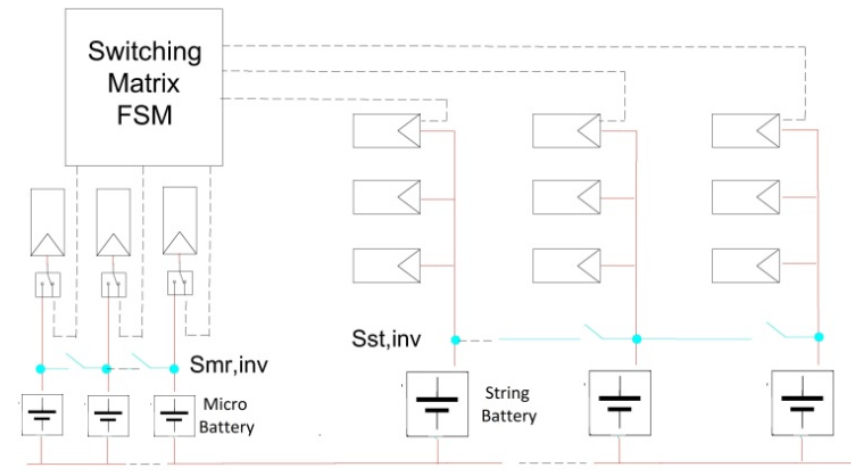

Figure 1: The proposed PVBS topology layout

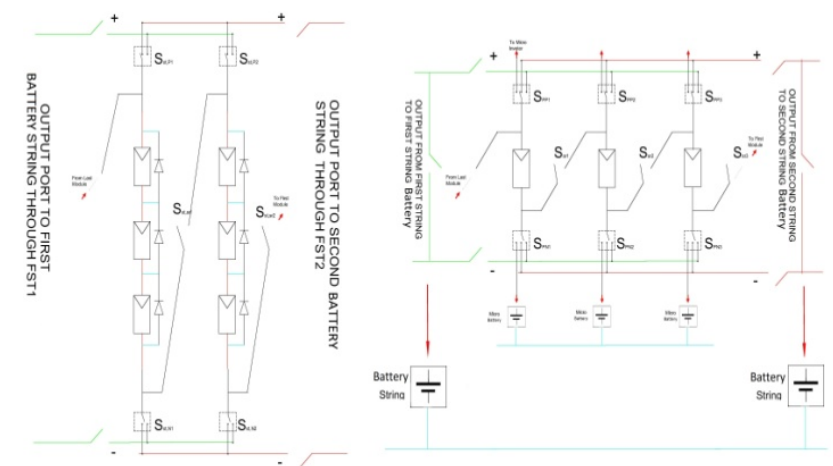

Figure 2: PVBS detailed structure

This study looks to improve the efficiency of the SEV using PV/Battery configuration, thus encouraging its more widespread adoption. In other words, the PV system interface, connections, and the configuration of the components are vital to achieving the optimal system performance adequate enough to encourage more widespread SEV. The performance of the PV system not only depends on operational conditions such as shadowing, high temperatures, or the degradation of the electrical characteristics of dusted panels, but it is also strongly dependent on the PV system configuration.

A novel configuration approach using an adaptive PV/Battery that establishes an interface between the PV modules, and the Battery for SEV is proposed. This structure discusses the concept from the generation point of view. In other words, the generated energy of the PV array is discussed without taken the charging and discharging characteristics of the battery into account.

\section{THE PROPOSED TOPOLOGY}

An adaptive PV system based on a flexible switching matrix (FSM) that is proposed in (3) to establish an interface between the PV modules and battery is implemented with some development made by the same author. The proposed configuration layout is shown in Fig.1. This layout offers a flexible connection to rearrange the PV modules according to the operational conditions to optimize battery charging in the SEV. . The proposed configuration uses a number of switches to perform the adaptive function of the structure. In that case, the PV/battery structure consists of three subsystems shown in Fig. 2. The first is a flexible string (FST), the second subsystem consists of flexible PV module (FPVM) that form an aid string (AST), and the third is bus structure. Each FST uses four switches while each FPVM uses three switches. The buses connect the strings and the modules together to the string/micro battery ( micro battery refers to single battery while string battery is string formed of series batteries) through switches, In this new configuration, the system includes only one adaptive string that can be used to overcome the excessive energy losses when shading occur across the PV strings. Fig 2 shows the layout of the proposed system. As of yet, the performance of the array is very effective and close to the optimal desired performance. Using this new idea, any existing system can be converted to adaptive system by adding one sting to (adaptive string (AST)) and adding some switches to the fixed PV string to convert them to be FST. This system can be applied any SEV that uses multiple PV strings and battery strings.

\section{SYSTEM OPERATION}

In normal operational condition, each FPVM is connected to a micro battery and each FST is connected to a string battery. At the terminals of the string, Each FST should have current/voltage sensors that can determine the condition of the modules and a charge controller while all FPVM should have individual I, V sensors and charge controllers.

In case of shading occurs across the FPVMs, the module's sensors will detect the shaded module and the matrix will disconnect it from the battery. The rest modules in the AST can work properly because they are connected separately to different micro battery.

In case of shadow occurs across some modules of FST, the sensors of the string, that are located at the terminals of each FST, will detect a voltage drop, which is the result of using bypass diode. This shading affects the $\mathrm{P}-\mathrm{V}$ characteristics of the FST as shown in Fig. 3(the blue curve with multiple peaks). This change in the P-V curves will shift the battery charging operating point from the maximum power point to a low power operating point. However, the controller will not be able to determine exactly which modules are shaded. However, the controller can calculate the exact number of missing modules in that string according to voltage deviation from the nominal voltage of the string. Two cases should be discussed in this situation; first, if shading occurs across modules of the same string, then FPVMs will be connected to this string. Second, if shadowing come across modules from different fixed strings, In this case, the AST string will be disassembled into FPVMs and these FPVMs will be distributed to the shaded FSTs. FPVMs will be connected in series to the shaded string to compensate the voltage drop. If there are some unused FPVMs, the controller will connect them to charge the micro batteries.

In this case, the system may still have the problem of multiple peaks in P-V curves, but the losses will be minimized.

Durham School of Architectural Engineering and Construction 
In case of none fully shaded modules, the resultant voltage of the FST will increase as the number of modules in the strings increases. The components and switches should be carefully designed to avoid overvoltage.

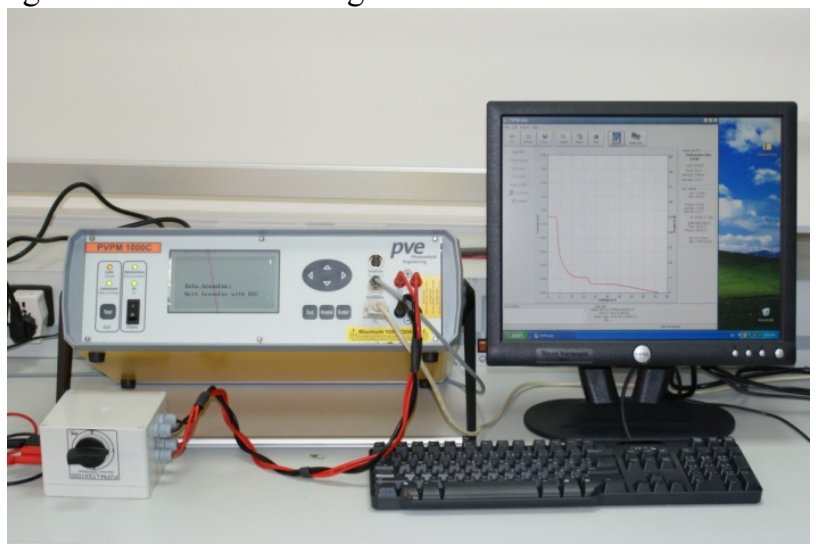

Figure 3: I-V Tracker Model Number PVPM 1000

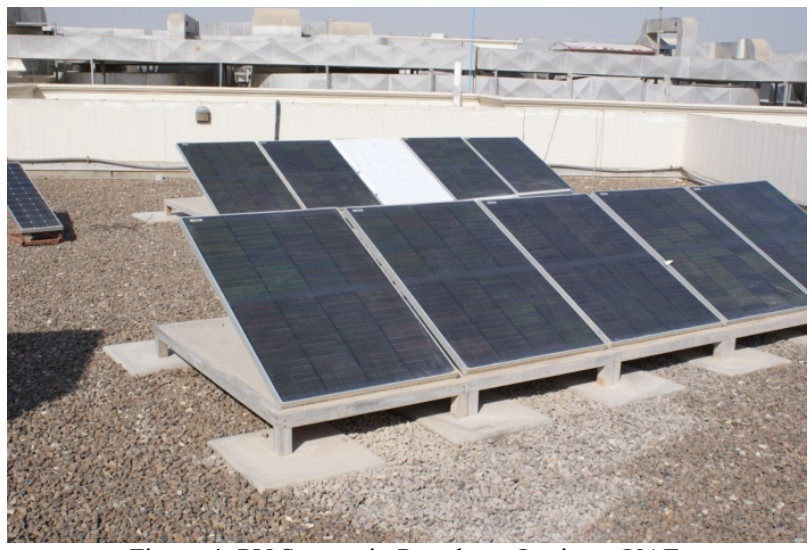

Figure 4: PV System in Petroleum Institute, UAE

\section{SIMULATION AND PRACTICAL RESULTS}

A MATLAB simulation model (4) is used in this study. Implementing this model, the simulation of the whole PV array can be achieved. The model is based on a group concept. This allows simulating the real array cases of different isolation and shadowing effects. The inputs of each group are adjustable. Solar irradiance, temperature, and the number of parallel strings in each group are considered as inputs. Shaded modules are also considered in this case. A special group will take care of simulating shading effect in the PV array. An actual test was conducted using two strings of three PV modules, $50 \mathrm{~W}$ each, to verify the proposed Idea. Fig 3 shows the I-V tracker model number PVPM 1000 which was used to measure the electrical characteristics of the PV system and transfer the measured data to Excel file. Fig 4 shows the actual PV system in Petroleum institute, UAE. The measurements were taken in February 23rd and 24th 2011.Shading over one, two, and three PV modules from different strings was examined using both the traditional system and the proposed configuration. Fig 5 and Fig 6 show the results of the simulation and practical experiments for different PV configurations. The battery characteristics curve is drawn for illustration purpose only.

\section{A. Results Analysis}

While the battery voltage is almost constant, the charging operating point of the battery is designed to be at the MPP in the P-V curve. As a result, the voltage value at the MPP of the improved adaptive P-V curve matches the optimal operating voltage of the normal operation (with no shading effect) that the battery works on. As can be seen, these results show that the proposed system has potential to increase the efficiency of the traditional PV system by smoothing the P-V curve to a single peak curve, thus extracting the maximum energy out of the PV array. The result analysis shows that the proposed system can minimize the losses in the system and provide flexible response to different operational conditions.

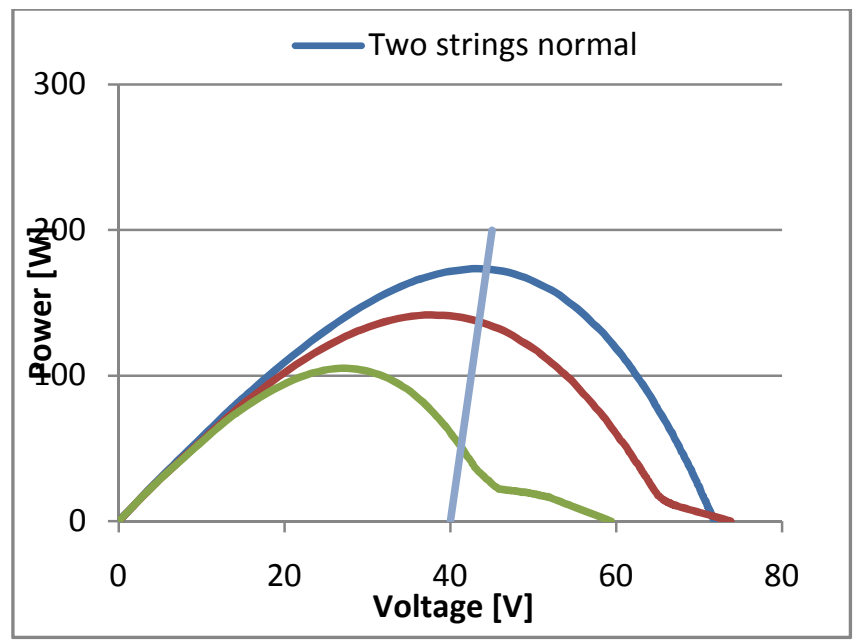

Figure 5: Practical results for two shaded modules

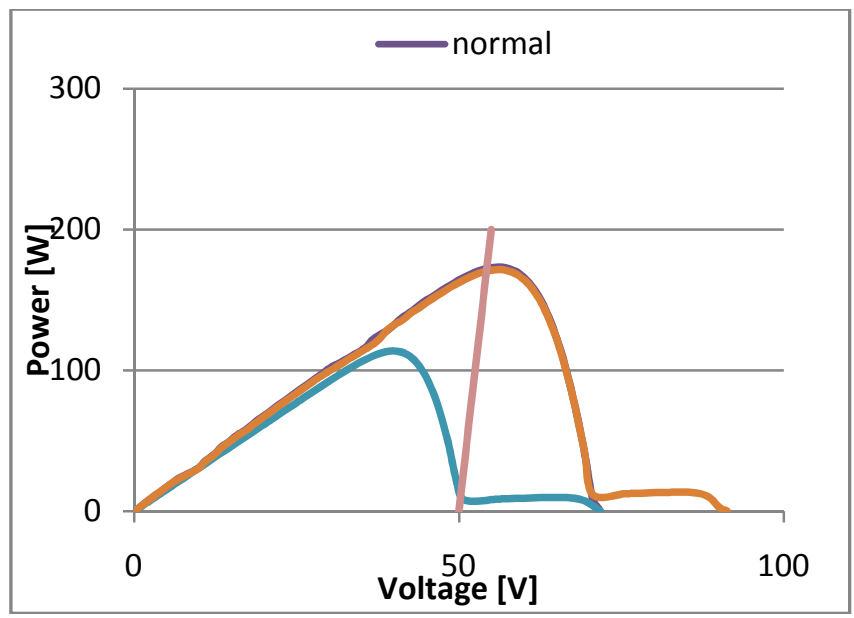

Figure 6: MATLAB Simulation results

\section{CONCLUSION}

This work has shown that adaptive photovoltaic technology can be implemented to assist the SEV. This study looks to improve the efficiency of the SEV using PV/Battery configuration, thus encouraging its more wide-spread adoption. This structure discusses the concept from the generation point of view. In other words, the generated energy of the PV array is 
discussed without taken the charging and discharging characteristics of the battery into account. The result analysis to calculate the actual efficiency improvement analysis is still in process and more result will be shown in the conference.

\section{REFERENCES}

[1] Auttawaitkul Y, Pungsiri B, Chammongthai K, Okuda M. In: A method of appropriate electrical array reconfiguration management for photovoltaic powered car. Circuits and systems, 1998. IEEE APCCAS 1998. the 1998 IEEE asia-pacific conference on; ; 1998. p. 201-4.
[2] Salameh ZM, Liang C. In: Optimum switching points for array reconfiguration controller. Photovoltaic specialists conference, 1990., conference record of the twenty first IEEE; ; 1990. p. 971,976 vol.2.

[3] Chaaban MA, Alahmad M, Neal J, Shi J, Berryman C, Cho Y, et al. In: Adaptive photovoltaic system. IECON 2010 - 36th annual conference on IEEE industrial electronics society; ; 2010. p. 3192-7.

[4] Patel H, Agarwal V. MATLAB-based modeling to study the effects of partial shading on PV array characteristics. Energy Conversion, IEEE Transactions on. 2008;23(1):302-10. 